\title{
Extrato aquoso de Cyperus rotundus no enraizamento de estacas lenhosas de Prunus persica cv. 'Chimarrita'
}

\author{
Aqueous extract of Cyperus rotundus on the rooting of Prunus persica cv. 'Chimarrita' cuttings
}

\section{Eliziane Scariot, Lisandro Tomas da Silva Bonome*, Henrique Von Hertwig Bittencourt e Cláudia Simone Madruga Lima}

Recebido em 09/10/2016 / Aceito em 09/12/2016

\section{RESUMO}

Embora os reguladores de crescimento do grupo das auxinas sejam comumente utilizados para induzir o enraizamento de estacas, nos últimos anos, as pesquisas têm voltado interesse para obtenção de métodos alternativos de indução da rizogênese em estacas de plantas de difícil propagação vegetativa, como a do pessegueiro cv. 'Chimarrita'. Isso faz com que a tiririca, planta encontrada em larga escala em grande parte do mundo, apresente-se como uma alternativa para a promoção de enraizamento de estacas, por possuir compostos fenólicos que apresentam efeito sinergístico com a auxina endógena. Diante do exposto, o objetivo deste trabalho foi avaliar a capacidade de enraizamento de estacas lenhosas de pessegueiro cv. 'Chimarrita' com a aplicação de diferentes concentrações do extrato aquoso de Cyperus rotundus L. em comparação com a aplicação do regulador de crescimento ácido indol-3-acético. Os tratamentos consistiram em diferentes concentrações de extratos aquosos do sistema radicular e de parte aérea de $C$. rotundus L. e do regulador de crescimento ácido indol-3-acético. Avaliou-se a percentagem de estacas vivas, de estacas enraizadas, de calos, o comprimento da raiz primária e a matéria seca do sistema radicular. O extrato aquoso de parte aérea e sistema radicular de C. rotundus L. não promove o enraizamento de estacas lenhosas de pessegueiro cv. 'Chimarrita' no período de 90 dias. A concentração de ácido indol-3-acético $500 \mathrm{mg} \mathrm{L}^{-1}$ é a que promove maior enraizamento de estacas lenhosas de pessegueiro.

PALAVRAS-CHAVE: estaquia, tiririca, pessegueiro, propagação vegetativa, ácido indol-3-acético.

\section{ABSTRACT}

Although growth regulators of the auxin group are normally used to induce rooting of cuttings, in recent years, research has been of interest to obtain alternative methods for the induction of rhizogenesis in cuttings of plants with difficult vegetative propagation, such as Peach tree cv. 'Chimarrita'. This makes the Cyperus rotundus L. a large-scale plant found in much of the world, an alternative for the induction of rooting in cuttings, because it has phenolic compounds that have a synergistic effect with the endogenous auxin. The objective of this study was to evaluate the rooting capacity of hardwood peach cuttings with the application of different concentrations of aqueous extract of $C$. rotundus $\mathrm{L}$. in comparison with the application of the plant growth regulator indole3 -acetic acid. The treatments consisted of different concentrations of the aqueous extracts of roots and shoots of $C$. rotundus $\mathrm{L}$. and the growth regulator indole-3-acetic acid. The percentage of live cuttings, rooted cuttings, callus, and the length of roots and dry matter of the root system were evaluated. The aqueous extract of shoot and root system of C. rotundus L. does not promote the rooting of hardwood peach cuttings cv. 'Chimarrita' within 90 days. The $500 \mathrm{mg}$ $\mathrm{L}^{-1}$ concentration of indole-3-acetic acid promotes greater rooting of the hardwood peach cuttings.

KEYWORDS: cutting, nutgrass, peach, vegetative propagation, indole-3-acetic acid.

Universidade Federal da Fronteira Sul, Laranjeiras do Sul, PR, Brasil.

* Autor para correspondência <lisandrobonome@gmail.com> 
A fruticultura representa um dos mais importantes segmentos da agricultura brasileira. Essa atividade assume um importante papel socioeconômico, por absorver intensa mão de obra familiar e resultar em alto rendimento econômico por área, permitindo a dinamização de economias locais estagnadas e com poucas alternativas de desenvolvimento (BUAINAIN \& BATALHA 2007).

Dentre as espécies de clima temperado cultivadas no Brasil, o pessegueiro (Prunus persica (L.) Batsch) se destaca por sua grande aceitação no mercado nacional e internacional, podendo ser consumido in natura ou processado em forma de doces, bolos, geleias, compotas e sucos. Atualmente, mais de 50 países cultivam Prunus persica, com produção em torno de 15,4 milhões de toneladas. $\mathrm{O}$ Brasil é considerado o $12^{\circ}$ maior produtor de Prunus persica (L.) Batsch, cuja produção é de 238,5 mil toneladas, representando apenas $1,1 \%$ do total da produção mundial (FAO 2013).

No Brasil, o pessegueiro é propagado através da enxertia por borbulhia de partes vegetativas de cultivares-copa (TOFANELLI et al. 2004). A estaquia é um método que poderia ser utilizado, nacionalmente, tanto para porta-enxertos como para cultivares-copa, pois, de acordo com FACHINELLO et al. (2005), este método apresenta uma série de vantagens, dentre as quais a maior facilidade de formação de grande número de mudas num curto espaço de tempo, baixo custo, fácil execução e maior uniformidade das plantas no pomar devido à fidelidade genética.

$\mathrm{Na}$ propagação via estaquia, a principal limitação são os baixos percentuais de enraizamento obtidos pela maioria das cultivares de pessegueiro utilizadas no território nacional (TOFANELLI et al. 2002). No entanto, esta dificuldade pode ser superada com o uso de reguladores de crescimento que induzem o enraizamento, como a auxina (CARDOSO et al. 2011).

A auxina torna mais eficiente a formação de raízes, pois além de acelerar o processo de enraizamento, melhora a qualidade das raízes formadas, produzindo mudas com maior uniformidade (VERNIER \& CARDOSO 2013). Além da auxina endógena do vegetal, existem aquelas produzidas sinteticamente, como o ácido indol-acético (AIA), o qual é comumente empregado na propagação vegetativa de diversas culturas de interesse econômico, incluindo o pessegueiro (PAIVA \& GOMES 2001).

Embora os reguladores de crescimento do grupo da auxina sejam normalmente utilizados na indução do enraizamento de estacas, nos últimos anos, as pesquisas têm voltado interesse para obtenção de métodos alternativos para a indução da rizogênese em estacas de plantas de difícil propagação vegetativa, como a do pessegueiro. Isso faz com que a tiririca, planta encontrada em larga escala em grande parte do mundo, apresente-se como uma alternativa para a promoção de enraizamento de estacas.

A tiririca é o nome popular dado a plantas da espécie Cyperus rotundus L.. Esta espécie pertence à família das Cyperaceae, e é uma planta daninha temida, pois além da capacidade de alastrar rapidamente nas áreas infestadas (ROSSAROLLA et al. 2013), apresenta agressividade na competição com outras plantas presentes em uma mesma área exigindo grande esforço para seu controle (KISSMANN 1997).

Embora, a tiririca seja amplamente conhecida pelos prejuízos que causa à agricultura, nos últimos anos, resultados de pesquisa tem sugerido a presença, tanto na parte aérea como nos tubérculos da planta, de compostos fenólicos que apresentam efeito sinergístico com a auxina endógena (FANTI 2008, ARRUDA et al. 2009).

Desta forma, este trabalho teve como objetivo comparar a aplicação de diferentes concentrações de extrato aquoso da parte aérea e do sistema radicular de Cyperus rotundus L. com a aplicação de auxina sintética (AIA), no enraizamento de estacas lenhosas de pessegueiro cv. 'Chimarrita'.

O experimento foi conduzido na Universidade Federal da Fronteira Sul, Campus Laranjeiras do Sul, PR. As estacas lenhosas de Prunus persica cultivar 'Chimarrita' foram obtidas de plantio comercial localizado no município de Laranjeiras do Sul, PR, situado nas coordenadas geográficas $25^{\circ} 24^{\prime} 40^{\prime \prime}$ de latitude Sul e $52^{\circ} 24^{\prime} 42^{\prime \prime}$ de longitude Oeste, a uma altitude de 840 metros acima do nível do mar. O clima, de acordo com a classificação de Köppen é do tipo Cfa, subtropical úmido.

As estacas apresentavam $20 \mathrm{~cm}$ de comprimento e $0,6 \mathrm{~cm}$ de diâmetro, sem a presença de folhas, oriundas da região mediana de plantas matrizes de pessegueiro cv. 'Chimarrita'.

As plantas de $C$. rotundus $\mathrm{L}$. foram obtidas em horta com mesma localização do plantio comercial de pessegueiro cultivar 'Chimarrita'. Após a coleta, as plantas de tiririca foram imediatamente transportadas para o laboratório de Fisiologia Vegetal da Universidade Federal da Fronteira Sul e 
seccionadas em parte aérea e sistema radicular (raízes e tubérculos).

Os extratos foram obtidos a partir da trituração, em liquidificador industrial, de $25 \mathrm{~g}$ da parte aérea e $25 \mathrm{~g}$ de sistema radicular em $250 \mathrm{ml}$ de água. Posteriormente, cada extrato foi filtrado em algodão seguido de filtragem em papel filtro e diluído nas concentrações de $25 \%, 50 \%$ e $75 \%$.

As estacas foram tratadas com hipoclorito de sódio $5 \%$ por 15 minutos em imersão e, em seguida, lavadas em água destilada corrente. Concluída a desinfecção, a base das estacas foi imersa por um período de 24 horas em $100 \mathrm{ml}$ para cada tratamento, sendo os tratamentos constituídos por testemunha com água destilada 100\% (TAD); extrato aquoso da parte aérea de C. rotundus 25\% (PACR25); 50\% (PACR50) e 75\% (PACR75); extrato aquoso de sistema radicular de C. rotundus 25\% (SRCR25); 50\% (SRCR50) e 75\% (SRCR75); solução de AIA $500 \mathrm{mg} \mathrm{L}^{-1}$ (AIA500); solução de AIA $1000 \mathrm{mg} \mathrm{L}^{-1}$ (AIA1000); solução de AIA $1500 \mathrm{mg} \mathrm{L}^{-1}$ (AIA1500).

Passadas 24 horas nos extratos e soluções, as estacas foram colocadas em substrato contendo terra de barranco, classificada como Latossolo Vermelho Distroférrico Típico (40\%), areia grossa autoclavada $(40 \%)$ e substrato comercial agrícola da marca Carolina Soil, contendo casca de pinus, vermicomposto e vermiculita (20\%). As estacas permaneceram no substrato por 90 dias, em casa de vegetação com temperatura média de $25^{\circ} \mathrm{C}\left( \pm 5^{\circ} \mathrm{C}\right)$, irrigação por aspersão, com umidade relativa média de $72 \%$.

Passados 30 dias do plantio das estacas foi realizado o desbaste. Nesse processo, foram retiradas todas as flores abertas e botões florais além das gemas foliares, deixando apenas a gema foliar apical da estaca.

Aos 90 dias após a implantação do experimento foram avaliadas a porcentagem de estacas vivas, porcentagem de estacas enraizadas, porcentagem de estacas com calos, comprimento da raiz primária $(\mathrm{cm})$, matéria seca do sistema radicular $(\mathrm{g})$, em estufa a $80^{\circ} \mathrm{C}$, até atingir peso constante.

O delineamento experimental utilizado foi o de blocos completos casualizados, com 10 tratamentos, 4 repetições e 7 estacas por repetição. Os dados obtidos foram submetidos à análise de variância (Anova) e posteriormente as médias foram comparadas pelo Teste de Scott-Knott $(\mathrm{p}<0,05)$ utilizando o software Assistat (SILVA \& AZEVEDO 2002).
Não houve diferença entre as médias dos tratamentos TAD, PACR25, PACR50, PACR75, SRCR25, SRCR50, SRCR75 e AIA1500 para a variável porcentagem de sobrevivência de estacas (Tabela 1). Já os tratamentos AIA500 e AIA1000 diferiram dos demais tratamentos, apresentando médias de sobrevivência de estacas de $50 \%$ e $46,43 \%$, respectivamente.

Em trabalho realizado por ARRUDA et al. (2009), testando a aplicação de extrato aquoso de tiririca em sapoti (Achras sapota L.), foi observado que quanto maior a concentração da dose do extrato aquoso de tubérculos da tiririca, maior era a sobrevivência das estacas de sapoti, ou seja, a relação é dose-dependente. Os autores observaram que aos 70 dias de avaliação a testemunha com água teve apenas $10 \%$ das estacas vivas. Já os tratamentos com $50 \%$ e $100 \%$ de extrato aquoso de tubérculo de tiririca tiveram $45 \%$ e $52 \%$ de sobrevivência, respectivamente.

Relacionando o experimento de ARRUDA et al. (2009) com o realizado no presente trabalho, podese observar que o tratamento que apresentou melhor resultado em relação à sobrevivência de estacas, não considerando a aplicação de regulador de crescimento, foi o tratamento com $50 \%$ de extrato aquoso do sistema radicular de tiririca (SRCR50), com 17,86\% de sobrevivência, mas que não diferiu da testemunha que apresentou $7,14 \%$.

FANTI (2008), avaliando o efeito de reguladores de crescimento (AIB e ANA) e extrato de folhas e de tubérculos de C. rotundus L. sobre o enraizamento de estacas caulinares de pingo-deouro (Duranta repens L.), não observou diferença estatística significativa para a porcentagem de estacas vivas entre os tratamentos.

Com relação a porcentagem de enraizamento, observa-se que os tratamentos com extratos de parte aérea e de tubérculos de tiririca, independentemente da concentração utilizada, não diferiram estatisticamente da testemunha e, portanto, não influenciaram no enraizamento do pessegueiro (Tabela 1).

Estes resultados corroboram com os observados por REZENDE et al. (2013) em estacas de Duranta repens L., no entanto, diferem dos observados por ARRUDA et al. (2009), que testando a aplicação de extrato aquoso de tubérculos de tiririca em estacas caulinares de sapoti, nas concentrações de $10 \%, 25 \%$, $50 \%$ e $100 \%$, observaram correlação positiva entre a concentração do extrato e o enraizamento, com valores de $47,5 \%, 55 \%, 70 \%$ e $77,5 \%$ de estacas enraizadas 
aos 40 dias após a implantação do experimento.

Os tratamentos AIA500 e AIA1000 diferiram estatisticamente da testemunha (TAD) e dos demais tratamentos, apresentando valores médios de estacas enraizadas de $46,43 \%$ e $42,86 \%$, respectivamente (Tabela 1). A dosagem de $1500 \mathrm{mg} \mathrm{L}^{-1}$ de AIA não foi eficaz em promover o enraizamento das estacas de pessegueiro. Segundo FACHINELLO et al. (2005), o teor adequado de auxina exógena, para estímulo de enraizamento, depende da espécie e da concentração da auxina existente no tecido. Assim, o incremento na concentração de auxina exógena, aplicada em estacas, pode provocar estímulo do enraizamento adventício até determinado valor ótimo, acima do qual o fitorregulador terá um efeito inibitório.

O enraizamento das estacas, neste experimento, provavelmente tenha sido influenciado negativamente pelo fato das estacas terem emitido botões florais em torno de 30 dias após o plantio. Isso ocorre por conta das estacas serem lenhosas e coletadas na época de seu repouso fisiológico. Assim, quando saíram da dormência as estacas emitiram folhas e flores imitando as condições normais como se estivessem na planta mãe a campo.

Esse mesmo fato foi observado por OLIVEIRA (2002) em seu experimento com estacas lenhosas de pessegueiro, as quais também emitiram flores, existindo assim, uma competição nas estacas por reservas de energia entre a regeneração vegetativa e a floração, podendo interferir diretamente na emissão de raízes.

Levando em conta a porcentagem de estacas que apresentaram estruturas chamadas calos (estacas vivas com formação de massa celular na base e sem a formação de raízes), pode se observar que mesmo não diferindo dos demais, o tratamento SRCR50 apresentou maior porcentagem de estacas calejadas, sugerindo que essas estacas ainda poderiam formar sistema radicular se permanecessem nos substratos por um maior período de tempo (Tabela 1).

Com o preparo da estaca, ocorre uma lesão nos tecidos que formam o caule. Nesta região, frequentemente se forma uma massa de células parenquimáticas desorganizadas e pouco diferenciadas, denominadas de calo. A formação de calo e de raízes são processos independentes na maioria das plantas. Entretanto, em algumas plantas, a formação de calo pode ser precursora da formação de raízes adventícias (HARTMANN et al. 2002).

A partir dos dados das estacas lenhosas enraizadas pode-se observar que as estacas de pessegueiro que apresentaram maior comprimento da raiz primária foram as tratadas com auxina, as quais não diferiram estatisticamente entre si, mas diferiram

Tabela 1 - Percentagem de sobrevivência, percentagem de enraizamento, percentagem de calos, comprimento da raiz primária e massa seca do sistema radicular das estacas lenhosas de pessegueiro. Laranjeiras do Sul, PR, 2015.

Table 1 - Survival percentage, rooting percentage, callus percentage, primary root length and dry mass roots of hardwood peach cuttings. Laranjeiras do Sul, PR, 2015.

\begin{tabular}{lccccc}
\hline Tratamento & $\begin{array}{c}\text { Sobrevivência } \\
(\%)\end{array}$ & $\begin{array}{c}\text { Enraizamento } \\
(\%)\end{array}$ & $\begin{array}{c}\text { Calos } \\
(\%)\end{array}$ & $\begin{array}{c}\text { C.R. } \\
(\mathbf{c m})\end{array}$ & $\begin{array}{c}\text { M.S.R } \\
(\mathrm{g})\end{array}$ \\
\hline TAD (Testemunha) & $7,14 \pm 4,12 \mathrm{~b}$ & $0,00 \pm 0,00 \mathrm{~b}$ & $3,57 \pm 3,57 \mathrm{a}$ & $0,00 \pm 0,00 \mathrm{~b}$ & $0,00 \pm 0,00 \mathrm{~b}$ \\
PACR25 & $0,00 \pm 0,00 \mathrm{~b}$ & $0,00 \pm 0,00 \mathrm{~b}$ & $0,00 \pm 0,00 \mathrm{a}$ & $0,00 \pm 0,00 \mathrm{~b}$ & $0,00 \pm 0,00 \mathrm{~b}$ \\
PACR50 & $7,14 \pm 4,12 \mathrm{~b}$ & $0,00 \pm 0,00 \mathrm{~b}$ & $0,00 \pm 0,00 \mathrm{a}$ & $0,00 \pm 0,00 \mathrm{~b}$ & $0,00 \pm 0,00 \mathrm{~b}$ \\
PACR75 & $0,00 \pm 0,00 \mathrm{~b}$ & $0,00 \pm 0,00 \mathrm{~b}$ & $0,00 \pm 0,00 \mathrm{a}$ & $0,00 \pm 0,00 \mathrm{~b}$ & $0,00 \pm 0,00 \mathrm{~b}$ \\
SRCR25 & $0,00 \pm 0,00 \mathrm{~b}$ & $0,00 \pm 0,00 \mathrm{~b}$ & $0,00 \pm 0,00 \mathrm{a}$ & $0,00 \pm 0,00 \mathrm{~b}$ & $0,00 \pm 0,00 \mathrm{~b}$ \\
SRCR50 & $17,86 \pm 8,99 \mathrm{~b}$ & $0,00 \pm 0,00 \mathrm{~b}$ & $14,29 \pm 10,10 \mathrm{a}$ & $0,00 \pm 0,00 \mathrm{~b}$ & $0,00 \pm 0,00 \mathrm{~b}$ \\
SRCR75 & $0,00 \pm 0,00 \mathrm{~b}$ & $0,00 \pm 0,00 \mathrm{~b}$ & $0,00 \pm 0,00 \mathrm{a}$ & $0,00 \pm 0,00 \mathrm{~b}$ & $0,00 \pm 0,00 \mathrm{~b}$ \\
AIA500 & $50,00 \pm 4,12 \mathrm{a}$ & $46,43 \pm 3,57 \mathrm{a}$ & $3,57 \pm 3,57 \mathrm{a}$ & $28,58 \pm 2,62 \mathrm{a}$ & $1,23 \pm 0,25 \mathrm{a}$ \\
AIA1000 & $46,43 \pm 15,84 \mathrm{a}$ & $42,86 \pm 15,43 \mathrm{a}$ & $3,57 \pm 3,57 \mathrm{a}$ & $21,71 \pm 5,12 \mathrm{a}$ & $1,42 \pm 0,63 \mathrm{a}$ \\
AIA1500 & $17,86 \pm 6,84 \mathrm{~b}$ & $17,86 \pm 6,84 \mathrm{~b}$ & $0,00 \pm 0,00 \mathrm{a}$ & $26,38 \pm 9,09 \mathrm{a}$ & $1,52 \pm 1,08 \mathrm{a}$
\end{tabular}

Médias \pm erro padrão seguidos pela mesma letra nas colunas não diferem significativamente pelo Teste de ScottKnott a 5\% de probabilidade de erro. C.R: Comprimento de raíz; M.S.R: Massa seca de raíz. 
dos demais tratamentos (Tabela 1).

OLIVEIRA (2002), testando aplicação de AIB, nas concentrações de 0,1500 e 3000 ppm, em estacas lenhosas e semilenhosas de pessegueiro não observou diferença significativa no comprimento das raízes entre os tratamentos. Todavia, RUFATO et al. (1999) observaram efeito positivo da aplicação de AIB sobre o comprimento das raízes de estacas lenhosas de pessegueiro para duas cultivares (Capdeboscq e Diamante), obtendo uma diferença de $0,02 \mathrm{~cm}$ sem aplicação de AIB para $0,55 \mathrm{~cm}$ com aplicação de 2000 $\mathrm{mgL}^{-1}$ de AIB.

Resultados similares foram observados por BORTOLINI (2006) e LIMA et al. (2006), os quais verificaram que aplicação de auxina sintética (AIB e ANA, respectivamente) na concentração de 1500 mg $\mathrm{L}^{-1}$ promoveu maior média numérica para $\mathrm{o}$ comprimento de raízes em estacas de Tibouchina sellowiana (quaresmeira) e Calliandra selloi (caliandra).

Por outro lado, FANTI (2008) observou que a maior média de comprimento da raiz primária $(7,0 \mathrm{~cm})$ em estacas caulinares de pingo-de-ouro foi obtida no tratamento com solução de AIB $500 \mathrm{mg} \mathrm{L}^{-1}$. Resultado semelhante, foi encontrado neste trabalho, em que as estacas lenhosas de pessegueiro que tiveram a maior média de comprimento foram as do tratamento com auxina sintética, AIA $500 \mathrm{mg} \mathrm{L}^{-1}$.

Em relação à matéria seca das raízes, observouse que os tratamentos com maiores médias em peso (gramas) de matéria seca de raiz foram aqueles tratados com auxina, independente da concentração utilizada, diferindo dos demais tratamentos (Tabela $1)$.

PEREIRA et al. (2012) em ensaio com aplicação de extrato aquoso de tubérculos e bulbos basais de tiririca $(0 \%, 50 \%, 75 \%$ e $100 \%)$ no enraizamento de estacas de maracujazeiro amarelo (Passiflora edulis Sims f. flavicarpa), não obtiveram nenhuma diferença significativa entre os tratamentos em relação a matéria seca de raiz.

Diante do exposto, torna-se necessário que novos experimentos, testando outras concentrações dos extratos, tempo de imersão das estacas e novas avaliações, para comprovar a eficácia da aplicação de extrato aquoso de tiririca em estacas lenhosas de pessegueiro.

O extrato aquoso de parte aérea e sistema radicular de Cyperus rotundus L. não promove o enraizamento em estacas lenhosas de pessegueiro cultivar 'Chimarrita' no período de 90 dias.

A concentração de AIA $500 \mathrm{mg} \mathrm{L}^{-1}$ é a que promove maior enraizamento em estacas lenhosas de pessegueiro.

\section{REFERÊNCIAS}

ARRUDA LAM et al. 2009. Atividade hormonal do extrato de tiririca na rizogênese de estacas de sapoti. In: IX Jornada de Ensino, Pesquisa e Extensão e Semana Nacional de Ciência e Tecnologia, Resumos... Recife: UFRPE. CDRom.

BORTOLINI MF. 2006. Uso do ácido indolbutírico na estaquia de Tibouchina selowiana (Cham.) Cogn.. Dissertação (Mestrado em Agronomia). Curitiba: UFPR. 85p.

BUAINAIN AM \& BATALHA MO. 2007. Cadeia produtiva de frutas. Brasília: IICA/MAPA/SPA. 102p.

CARDOSO C et al. 2011. AIA e substratos no enraizamento de estacas de pessegueiro 'Okinawa' coletadas no outono. Semina: Ciências Agrárias 32: 1307-1314.

FACHINELLO JC et al. 2005. Propagação de plantas frutíferas. Brasília: Embrapa Informação Tecnológica. $221 \mathrm{p}$.

FANTI FP. 2008. Aplicação de extratos de folhas e de tubérculos de Cyperus rotundus L. (Cyperaceae) e de auxinas sintéticas na estaquia caulinar de Duranta repens L. (Verbenaceae). Dissertação (Mestrado em Botânica). Curitiba: UFPR. 69p.

FAO - Food and Agriculture Organization of The United Nations. 2013. Base de dados estatísticos - Faostat Agriculture. <www.fao.org.br>. Acesso em: 22 nov. 2016. HARTMANN HT et al. 2002. Plant propagation: principles and practices. Nova Jersey: Prentice-Hall. 880p.

KISSMANN KG. 1997. Plantas infestantes e nocivas Plantas inferiores: monocotiledôneas. 2.ed. São Paulo: BASF. 825p.

LIMA DM. et al. 2006. Substratos e concentrações de ácido naftaleno acético no enraizamento de estacas semilenhosas de Calliandra selloi e Calliandra tweediei. Scientia Agraria 7: 105-111.

OLIVEIRA AP. 2002. Uso do ácido indolbutírico no enraizamento de estacas semilenhosas e lenhosas de pessegueiro. Dissertação. (Mestrado em Agronomia). Passo Fundo: FAMV/UPF. 96p.

PAIVA HN \& GOMES JM. 2001. Propagação vegetativa de espécies florestais. Viçosa: Editora UFV. 46 p. (Série cadernos didáticos, 83).

PEREIRA EO. et al. 2012. Enraizamento de estacas de maracujazeiro cultivadas em diferentes substratos e tratadas com extratos de tiririca. Nucleus 9: 93-102.

REZENDE FPF et al. 2013. Aplicação de extratos de folhas e tubérbulos de Cyperus rotundus L. e de auxinas sintéticas na estaquia caulinar de Duranta repens L. Revista Brasileira de Plantas Medicinais 15: 639-645. 
ROSSAROLLA MD et al. 2013. Extrato de tiririca induz maior brotação em miniestacas de acerola. In: 8 Congresso Brasileiro de Agroecologia Resumos... Porto Alegre: Cadernos de Agroecologia. 8: 1-5.

RUFATO L et al. 1999. Efeito de diferentes concentrações de floroglucinol no enraizamento de estacas de duas cultivares de pessegueiro (Prunus persica L. Batsch) tratadas com AIB. Revista Brasileira de Fruticultura 21: 297-300.

SILVA FAZ \& AZEVEDO CAV. 2002. Versão do programa computacional Assistat para sistema operacional Windows. Revista Brasileira de Produtos Agroindustriais. 4: 71-18.

TOFANELLIMBDetal.2002. Efeito doácido-indolbutírico no enraizamento de estacas de ramos semilenhosos de pessegueiro. Pesquisa Agropecuária Brasileira 37: 939944.

TOFANELLI MBD et al. 2004. 2,6-di-hidroxiacetofenona no enraizamento de estacas semilenhosas de pessegueiro. Revista Brasileira de Fruticultura 26: 366-368.

VERNIER RM \& CARDOSO SB. 2013. Influência do ácido indol-butírico no enraizamento de estacas em espécies frutíferas e ornamentais. Revista Eletrônica de Educação e Ciência 3: 11-16. 